\title{
ESCOLA PROFESSORA MARIA ISABEL BARBOSA NEGRÃO - ESTUDO SOBRE OS ESTILOS ARQUITETÔNICOS DE EDIFÍCIOS ESCOLARES EM PRESIDENTE PRUDENTE -
} SP

Jacqueline Magalhães Saab, Letícia Bortolo Martins, Mayara Pissutti Albano, Sibila Corral de Arêa Honda, Fabrícia Dias da Cunha de Moraes Fernandes Borges

Universidade do Oeste Paulista - UNOESTE, curso de Arquitetura e Urbanismo, Presidente Prudente, SP. Arquiteta Urbanista, Global Planejamento. E-mail: fabricia.arquiteta@gmail.com; sibila.honda@sibila.arq.br

\section{RESUMO}

Através da presente pesquisa objetivou-se desenvolver levantamento e análises dos edifícios de escolas de Ensino Fundamental I, tendo como objeto de estudo a escola Professora Maria Isabel Barbosa Negrão na cidade de Presidente Prudente, localizada no oeste do estado de São Paulo. Tais levantamentos visavam a relacionar a tipologia construtiva, o estilo arquitetônico vigentes no período de implantação da referida escola. Para tal, a metodologia adotada foi de levantamentos bibliográficos, documentais e levantamentos em campo. A importância da pesquisa é justificada pela necessidade de espaços e estruturas adequadas às crianças de até dez anos de idade, para efetivo desenvolvimento motor, cognitivo, social e educacional.

Palavras chave: Educação Fundamental, Escola, Edificação, Estilo Arquitetônico, Presidente Prudente - SP.

\section{SCHOOL PROFESSORA MARIA ISABEL BARBOSA NEGRÃO - STUDY ON THE ARCHITECTURAL STYLES OF SCHOOL BUILDINGS IN PRESIDENTE PRUDENTE - SP}

\begin{abstract}
The objective of this research is to develop a survey and analysis of the buildings of Elementary School I, with the purpose of studying the School Professora Maria Isabel Barbosa Negrão in the city of Presidente Prudente, located in the west of the state of São Paulo. These researches aim to relate the constructive typology, the architectural style in force in the period of implementation of this school. Therefore, the methodology adopted will be bibliographical, documentary and field analysis. The importance of the research is justified by the need for appropriate spaces and structures for children up to ten years for effective motor, cognitive, social and educational development.
\end{abstract}

Keywords: Fundamental Education, School, Edification, Architectural Style, Presidente Prudente SP.

\section{INTRODUÇÃO}

A Constituição Federal de 1988 afirma que a educação Fundamental é de competência comum aos Estados e Municípios, que contempla a provisão de escolas e também toda a estrutura necessária, as vagas e os professores. Na contemporaneidade, a educação fundamental é subdividida em Fundamental I e II, sendo que crianças entre 6 anos (incompletos) e 10 anos, estão inseridas no Ensino Fundamental I, que se inicia no 1으 e finaliza no 5으 ano. Entretanto, o Estado de São Paulo municipalizou o ensino Fundamental I.

Para que se tenha um ensino de qualidade, faz-se necessário que o espaço físico também o seja, de modo particular, quando direcionado a crianças de até 10 anos de idade, visto que a totalidade do espaço destinado ao ensino deve ser adequada para seus devidos fins, desde a 
edificação até os mobiliários precisam ter dimensões, cores, texturas, adequadas que permitam e auxiliem o desenvolvimento cognitivo, motor, social e educacional.

As tipologias das edificações escolares possuem relação com as teorias pedagógicas vigentes em diferentes períodos da história da educação, e também com os equipamentos ofertados e com estilos arquitetônicos de cada época. Contudo, pretende-se, através da pesquisa proposta, relacionar estudos da área de Arquitetura e Urbanismo com edifícios de Ensino Fundamental I, para tanto, escolheu-se a escola Maria Isabel Barbosa Negrão como objeto de estudo, esta localiza-se no conjunto habitacional Mário Amato, na cidade de Presidente Prudente SP.

O processo de urbanização brasileiro acentuou-se a partir da década de 1960, influenciando a estrutura intraurbana, bem como da sociedade, gerando um aumento veloz da necessidade de serviços públicos como moradia, saúde e educação; sendo a educação um dos mais importantes e, para ser ofertada é necessário o estabelecimento da estrutura necessária, no entanto, a construção e manutenção de unidades escolares e da estrutura necessária possuem custos altos, fato que dificulta a ampliação da rede de escolas de ensino público.

Atualmente, no estado de São Paulo, a responsabilidade de avaliar e coordenar projetos Arquitetônicos feitos por escritórios e arquitetos terceirizados e contratados é a Fundação para o Desenvolvimento da Educação (FDE) (DELIBERADOR, 2010).

Escolano (apud VIÑAO, 1995) afirma que o espaço institui um sistema de valores, que recobre símbolos estéticos, culturais e ideológicos; resultando em interiorização de comportamentos e de representações sociais. Dessa forma, visa-se aprofundar o conhecimento relativo à área desta pesquisa.

O objetivo deste estudo foi analisar, identificar e desenvolver o levantamento projetual das edificações atuais de escola pública de Ensino Fundamental I inseridas na malha urbana de Presidente Prudente - SP. A presente pesquisa compõe o projeto de pesquisa docente (EDIFÍCIOS DE EDUCAÇÃO FUNDAMENTAL EM PRESIDENTE PRUDENTE-SP - RELAÇÃO ENTRE TIPOLOGIAS ARQUITETÔNICAS, POLÍTICAS PÚBLICAS DE EDUCAÇÃO E AS TEORIAS PEDAGÓGICAS VIGENTES protocolo 2491), que visa a analisar e identificar as edificações atuais de escola pública de ensino fundamental inseridas na malha urbana de Presidente Prudente - SP, segundo suas datas de projeto e execução, relacionando-as ao período histórico da arquitetura, ou seja, aos estilos arquitetônicos vigentes em cada momento.

Para esse trabalho, o edifício de objeto de estudo foi o da Escola Maria Isabel Barbosa Negrão, desenvolvendo levantamento métrico da edificação analisada e elaborar as peças gráficas de projeto, levantar a data de projeto e execução da edificação analisada, e o estilo arquitetônico, verificar também se o edifício de ensino fundamental teve como diretrizes projetuais do momento histórico.

\section{METODOLOGIA}

Método é a somatória de diferentes processos necessários para que o pesquisador alcance os resultados objetivos necessários. A metodologia utilizada nesta pesquisa foi desenvolvida através da investigação qualitativa, utilizando-se de levantamento bibliográfico, de pesquisa documental, de levantamentos físicos arquitetônicos in loco da escola supracitada, com observação sistemática da mesma.

À priori foi realizado levantamento bibliográfico em livros e periódicos com as principais obras referentes às políticas educacionais brasileiras e a relação com os projetos arquitetônicos dos edifícios escolares. Numa segunda fase, foram desenvolvidas pesquisas documentais para verificação da data do projeto e de execução do edifício escolar através dos documentos existentes na própria escola, cujo acesso foi previamente autorizado pela Secretaria Municipal de Educação, através dos documentos e autorizações concedidas para o Programa de Parcelamento 
de Débitos no qual o projeto de iniciação científica, que gerou os presentes resultados está vinculado. A análise documental é, conforme afirma Lüdke e André (1986, p. 38), uma “uma técnica valiosa de abordagem de dados qualitativos, seja complementando informações obtidas por outras técnicas, seja desvelando aspectos novos de um tema ou problema".

Posteriormente foram realizados levantamentos in loco, mediante autorização prévia já concedida com medições do edifício para que sejam desenvolvidas peças gráficas de projeto arquitetônico que foram representadas com o auxílio do software AutoCad.

Após a conclusão das fases iniciais foram desenvolvidas análises comparativas sistemáticas através da observação intensiva, visando a analisar se o projeto da escola estudada se encontra em conformidade ou desconformidade com as diretrizes projetuais apresentadas pela Fundação para o Desenvolvimento da Educação - FDE da Secretaria de Educação do Estado de São Paulo.

\section{ESCOLA MARIA ISABEL BARBOSA NEGRÃO}

Equipamentos urbanos e uma infraestrutura de qualidade são essenciais para o bom funcionamento de uma área urbana. A educação é uma dessas grandes áreas e, de acordo com o artigo 205 da Constituição Federal Brasileira (1988), é um direito de todos e dever da família e do Estado em promovê-la. De tal modo, além do Governo Federal, os Estados e os Municípios, são responsabilizados pela execução da Educação no Brasil.

Assim, segundo Oliveira (2009), o método de Municipalização do Ensino Fundamental se fortaleceu nos anos 1990, estabelecendo então que o Ensino Fundamental seja de responsabilidade das Prefeituras Municipais, o Ensino Médio a comprometimento dos Governos Estaduais e o Ensino Superior a cargo do Governo Federal.

O edifício escolar público, objeto de estudo do presente trabalho, atende ao Ensino Fundamental I, com 504 crianças entre 4 a 10 anos, do Pré I ao 5o ano, onde 400 alunos são regulares, 104 fazem parte da atividade complementar e 20 da atividade espacial. Desse modo, torna-se importante a verificação e adequação do prédio para um melhor aproveitamento do ensino e possibilitando assim um melhor aperfeiçoamento social, cognitivo, educacional e motor de seus alunos.

A escola ocupa atualmente o antigo prédio do SESI - Mario Amato visto que a única escola do bairro era essa. Com a mudança da instituição privada para um novo prédio, houve a necessidade de realocar a Escola Maria Isabel Barbosa Negrão no ano de 2014. Sendo assim, hoje ela está situada na Rua Maurílio Fernandes, número 496, Bairro Mario Amato, na cidade de Presidente Prudente - SP, não mais no bairro vizinho, Ana Jacinta, como no início da pesquisa.

O edifício foi concluído em 28 de fevereiro de 1994, período característico da arquitetura contemporânea. De acordo com o website Galeria da Arquitetura (2015), a arquitetura contemporânea brasileira teve início em meados da década de 1980 e permanece até hoje. Possui uma linguagem diferente, onde cada seguimento realiza uma releitura da arquitetura passada, porém seu conceito está voltado a uma forte reintegração do racionalismo com tendências minimalistas.

A arquitetura contemporânea, segundo Luccas (2008), possui referencias do passado "[...] uma arquitetura progressiva em sintonia com ideias construtivas, como a síntese e rigor das formas, além da retomada da confiança na tecnologia, em substituição mais dosada ao habitual". De acordo com Fracassoli (2013), "A arquitetura contemporânea é o resultado físico-espacial do encontro equilibrado e harmônico entre dois mundos: o racional e o sensível".

O projeto arquitetônico desenvolve-se por toda a extensão da quadra em que está implantado e está separado por três blocos distintos (figura 1). No bloco 1 está localizada a recepção, secretaria, diretoria, sala da professora comunitária, sala da orientação pedagógica, copa e banheiros dos professores, sala dos professores, das salas de recursos multifuncionais, sala de vídeo, biblioteca, sala de informática, banheiro feminino e masculino para os alunos e seis salas 
de aula. No bloco 2 está localizado a brinquedoteca, almoxarifado, quatro salas de aula, banheiro feminino e masculino para estudantes, refeitório, cozinha, despensa da cozinha, palco, coxia com banheiro, copa, despensa, lavanderia e banheiro feminino e masculino para funcionários. $\mathrm{O}$ bloco 3 é destinado aos alunos especiais e possui três salas de aula, um banheiro para professores, um banheiro feminino e um masculino para estudantes e uma despensa.

Figura 01. Implantação e setorização

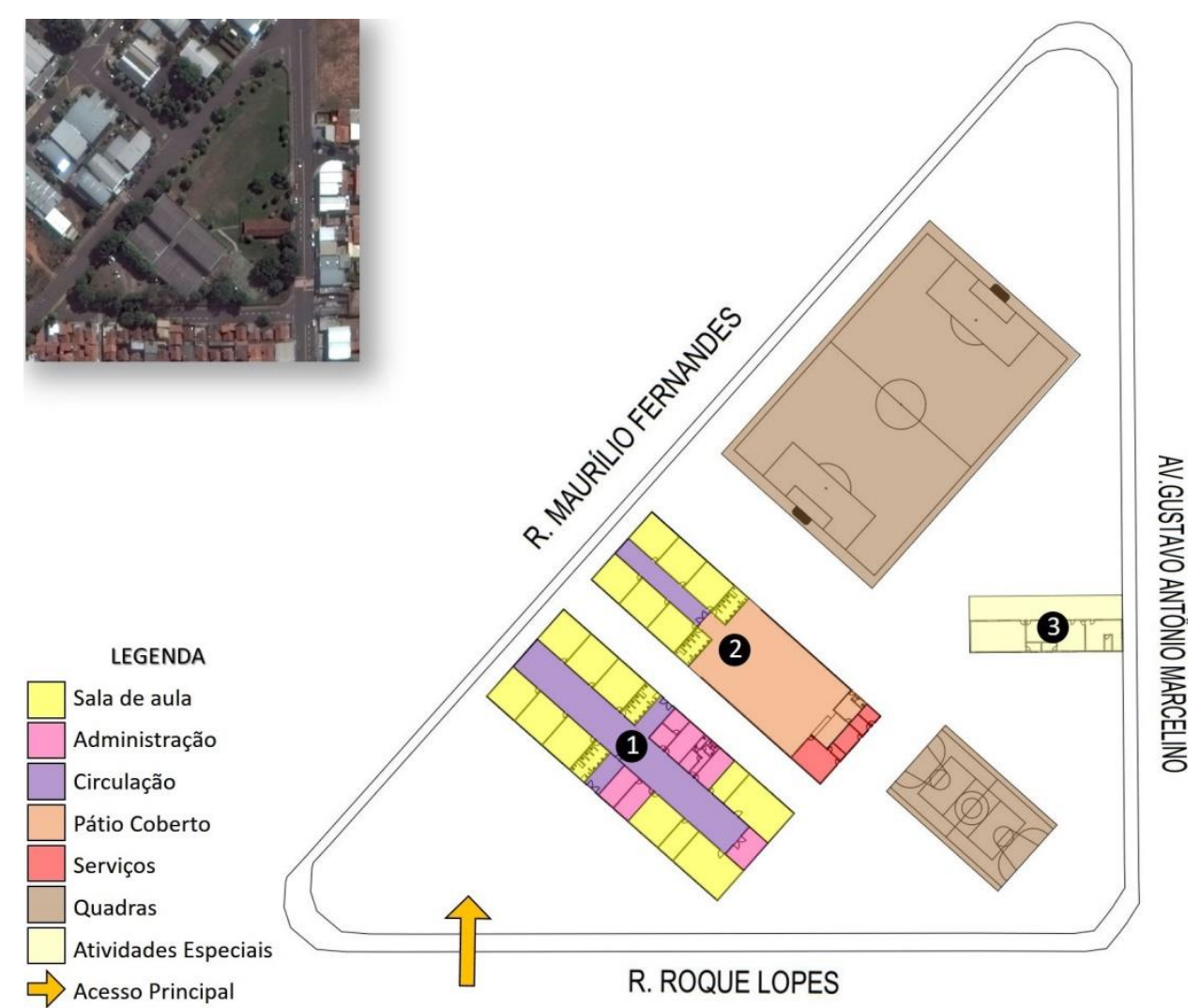

Fonte: autoras (2017).

As análises arquitetônicas do edifício apresentam que a organização dos espaços é de forma funcional e racionalista; há a presença do elemento vazado Cobogó (figura 2) no pátio coberto que possui função se separar o interior do prédio com o exterior sem causar prejuízo na luz natural e na ventilação; as fachada (figura 3) possui formas simples, geométricas e sem ornamentos; as janelas e portas (figura 4) são grandes; e, o uso do concreto armado em toda a escola. 
Figura 02. Bloco 2 com o elemento Cobogó

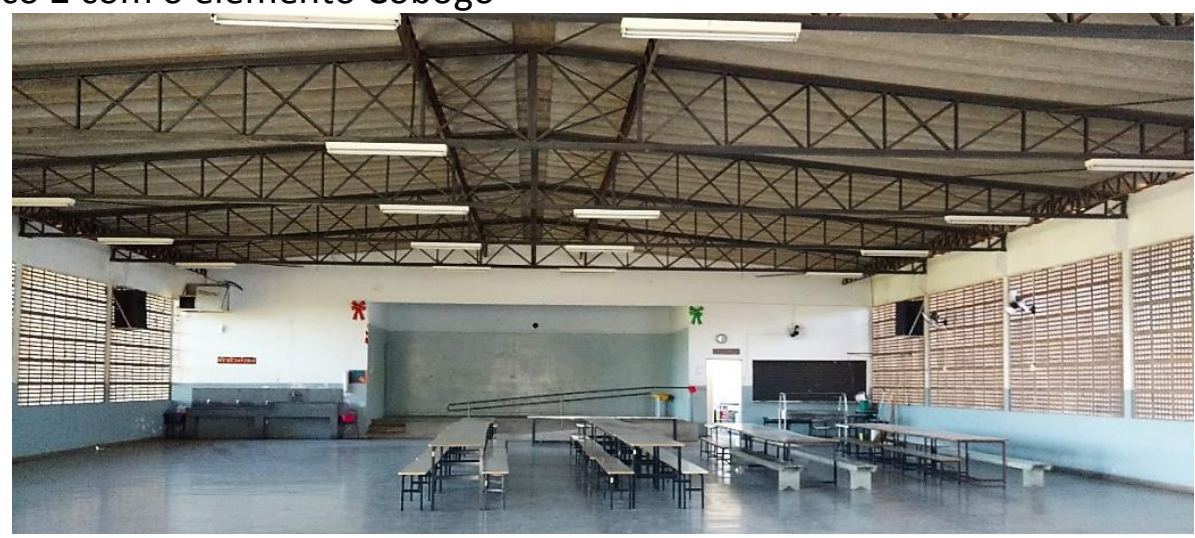

Fonte: autoras (2017).

Figura 03. Fachada

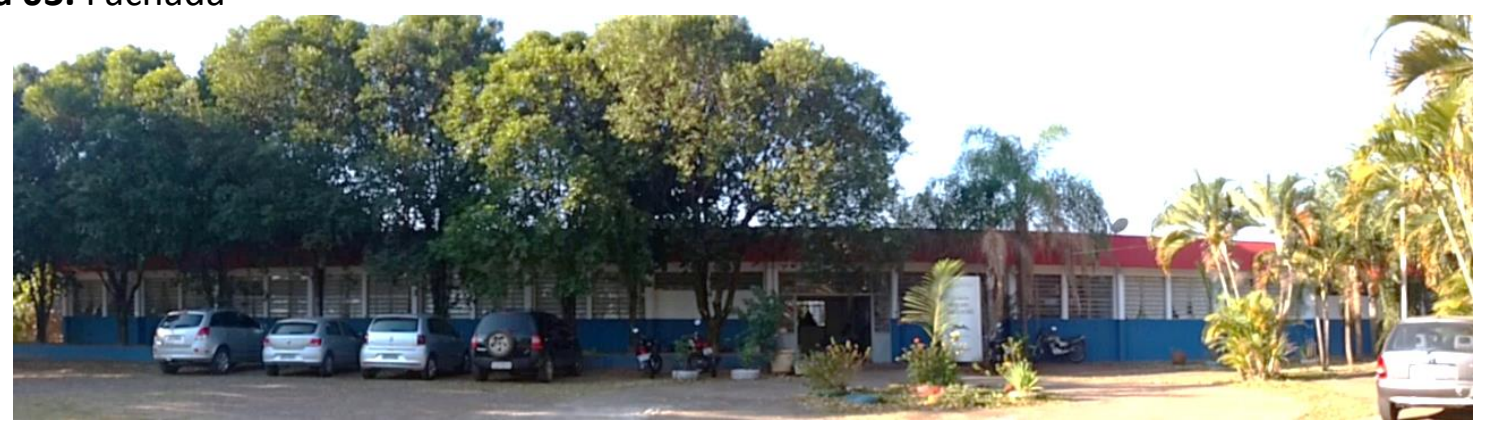

Fonte: autoras (2017).

Figura 04. Janelas e portas

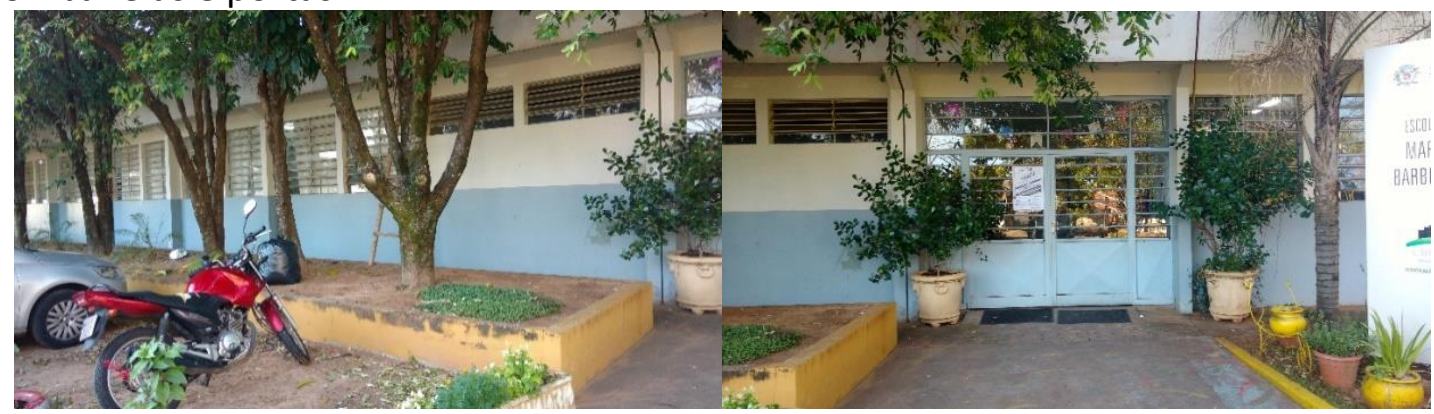

Fonte: autoras (2017).

Os resultados obtidos no presente trabalho indicam que, mesmo construída em um período marcado pela arquitetura contemporânea, os elementos da escola em estudo remetem aos padrões construtivos da arquitetura modernista tardia. Deste modo, a falta de estilo arquitetônico definido pode estar ligada a padronização associada a meios rápidos e econômicos de construção.

\section{CONCLUSÃO}

Em função das informações e dados obtidos ao longo da presente pesquisa, conclui-se que a escola Maria Isabel Barbosa Negrão não possui um estilo arquitetônico definido e remete alguns de seus elementos ao modernismo, ainda que a arquitetura da época era a contemporânea. 0 reflexo das políticas públicas da época transparece no edifício até os dias de hoje. 


\section{REFERÊNCIAS BIBLIOGRÁFICAS}

ABASCAL. Fontes e diretrizes da arquitetura contemporânea: uma reflexão crítica a respeito dessa genealogia. Cadernos de Pós-Graduação em Arquitetura e Urbanismo, v. 5, n. 1, 2008.

BRASIL. Constituição Federal Brasileira. 1988.

DELIBERADOR, Marcella S. O processo de projeto de arquitetura escolar no Estado de São Paulo: caracterização e possibilidades de intervenção. (Dissertação de Mestrado) Campinas: UNICAMP. 2010.

FRACASSOLI, Igor. Fundamentos da Arquitetura Contemporânea. Siegbert Zanettini; 2013. Disponível em: <http://www.archdaily.com.br/br/01-106915/fundamentos-da-arquiteturacontemporanea-slash-siegbert-zanettini>. Acesso em 07.02.2017.

GALERIADAARQUITETURA. A Arquitetura Contemporânea Brasileira; 2015. Disponível em: <http://www.galeriadaarquitetura.com.br/Blog/post/a-arquitetura-contemporanea-brasileira>. Acesso em: 31.02.2017.

LUCCAS, Luís. H. H. Arquitetura contemporânea no Brasil: da crise dos anos setenta ao presente promissor; $2008 . \quad$ Disponível em: <http://www.vitruvius.com.br/revistas/read/arquitextos/09.101/99>. Acesso em: 07.02.2017.

LUDKE, Menga e ANDRÉ, Marli. E. D. A. Pesquisa em Educação: Abordagens qualitativas. São Paulo: EPU, 1986.

MARISCO, Luciane Maranha de Oliveira. A norma e o fato: abordagem analítica da segregação sócio-espacial e exclusão social a partir dos instrumentos urbanísticos. Tese (Doutorado), Faculdade de Ciências e Tecnologia da Universidade Estadual Paulista, Presidente Prudente-SP, 2003.

OLIVEIRA, Clenilde. M. A Municipalização da Educação no Estado de São Paulo. In: IX Congresso Nacional de Educação - EDUCERE III Encontro Sul Brasileiro de Psicopedagogia. 2009. PUCPR.

VIÑAO, Frago A. História de la educación e historia cultural: posibilidades, problemas, cuestiones. In: Revista Brasileira de Educação. No. 0, PP.63-82. 1995. Disponível em: http://educa.fcc.org.br/scielo.php?pid=S1413-24781995000100005\&script=sci_arttext. Acesso em 05.02.2017. 